\title{
RESEARCH
}

Open Access

\section{Coverage determinants of breast cancer screening in Flanders: an evaluation of the past decade}

\author{
L. Ding ${ }^{1,2}$, S. Jidkova ${ }^{3,4}$, M. J. W. Greuter ${ }^{5,6}$, K. Van Herck ${ }^{3,4}$, M. Goossens ${ }^{4}$, P. Martens ${ }^{4}$, G. H. de Bock ${ }^{1 *}$ and \\ G. Van $\mathrm{Hal}^{2,4}$
}

\begin{abstract}
Background: Breast cancer (BC) is the most common cancer in women in the developed world. In order to find developing cancers in an early stage, BC screening is commonly used. In Flanders, screening is performed in and outside an organized breast cancer screening program (BCSP). However, the determinants of BC screening coverage for both screening strategies are yet unknown.

Objective: To assess the determinants of BC screening coverage in Flanders.

Methods: Reimbursement data were used to attribute a screening status to each woman in the target population for the years 2008-2016. Yearly coverage data were categorized as screening inside or outside BCSP or no screening. Data were clustered by municipality level. A generalized linear equation model was used to assess the determinants of screening type.
\end{abstract}

Results: Over all years and municipalities, the median screening coverage rate inside and outside BCSP was 48.40\% (IQR: 41.50-54.40\%) and 14.10\% (IQR: 9.80-19.80\%) respectively. A higher coverage rate outside BSCP was statistically significantly $(P<0.001)$ associated with more crowded households (OR: 3.797, 95\% Cl: 3.199-4.508), younger age, higher population densities (OR: 2.528, 95\% Cl: 2.455-2.606), a lower proportion of unemployed job seekers (OR: 0.641, 95\% Cl: 0.624-0.658) and lower use of dental care (OR: 0.969, 95\% Cl: 0.967-0.972).

Conclusion: Coverage rate of BC screening is not optimal in Flanders. Women with low SES that are characterized by younger age, living in a high population density area, living in crowded households, or having low dental care are less likely to be screened for BC in Flanders. If screened, they are more likely to be screened outside the BCSP.

Keywords: Breast neoplasms, Mammography, Mass screening, Coverage rate, Social determinants of health

\footnotetext{
* Correspondence: g.h.de.bock@umcg.nl

${ }^{1}$ Department of Epidemiology, University Medical Center Groningen,

University of Groningen, Groningen, The Netherlands

Full list of author information is available at the end of the article
}

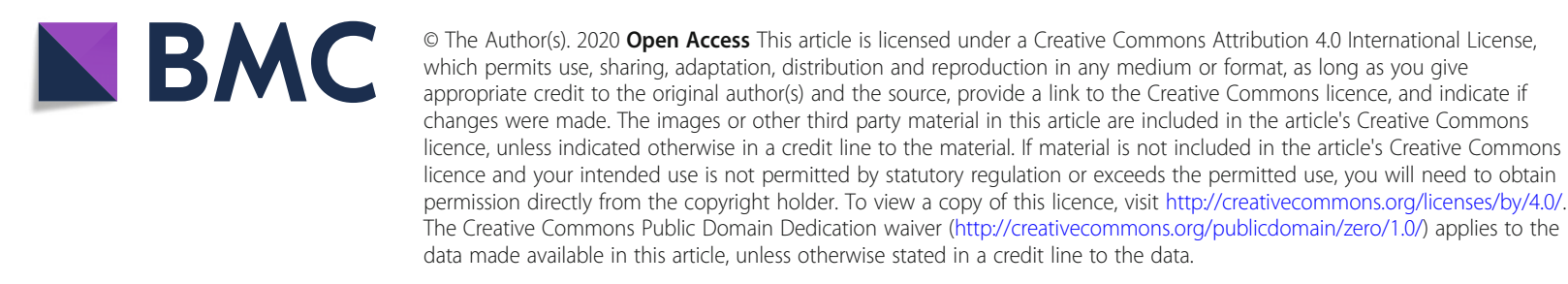




\section{Background}

Belgium is among the countries with the highest female breast cancer (BC) incidence and mortality worldwide [1]. In 2018, the age-standardized BC incidence and mortality rate of Belgium women were $113.2 / 100,000$ and 22.2/100,000 person-years, respectively, which is higher than the estimate for the whole Western European region (92.6 and 15.5/100,000 person-years, respectively) $[1,2]$. While sufficient evidence has indicated that mammography screening has the potential to initiate early diagnosis and treatment for $\mathrm{BC}$ and lower BC mortality, the effect of mammography screening relies on the degree to which women participate in screening [3].

In most of the high income countries, women are recommended to participate in an organized $\mathrm{BC}$ screening program (BCSP), where quality is warranted by systematic quality control measures [4]. Outside this program, with the aim to screen more of the eligible women, spontaneous screening is also endorsed in some countries, such as in Belgium [5], France [6] and Switzerland [7]. The coverage of $\mathrm{BC}$ screening, defined as the percentage of screened women in the total eligible population within the specific interval of routine screening [8], is an important indicator for the evaluation of the effectiveness of screening [4, 9]. However, the average coverage rate in 2016 across OECD countries was only 57.4\% [10]. As for Flanders, the coverage rate of BCSP in 2017 was only 49 and $13 \%$ was screened outside the BCSP [11].

Many factors have previously been shown to be associated with a reduced coverage level of BCSP. A systematic review summarized that the barriers to $\mathrm{BC}$ screening fell into three categories: 1 ) health care system level barriers, such as lack of health care providers and economic barriers; 2) social barriers, such as lack of social support and cultural norms opposed to BC screening; and 3) individual level barriers, such as lack of cancer knowledge and beliefs, negative expectations of screening, and distrust of the medical system [12]. However in this review, the majority of the included studies relied on self-reported data, studies with random and convenience samples were pooled, and evidence was only qualitatively synthesized. Many other studies have also provided quantitative evidence on these hampering factors. Among them, economic related barriers were the most commonly studied factors and results showed that low income [13], crowded housing condition [14], unemployment [15] and residing in social-economically deprived areas [16] are predictors of a lower BC screening coverage rate. Lack of a regular health care provider is associated with a reduced coverage rate of screening both inside [17] and outside a BCSP [7]. Other individual level characteristics include residential instability [18], being an immigrant [19], physical disability [20], and having one or more chronic diseases [21]. Only a relatively small amount of studies are dedicated to exploration of the determinants of screening outside a BCSP. Regular visits to a gynecologist, being employed and low esteem of the quality of the population screening program are associated with an increased attendance to screening outside a BCSP $[6,7,22]$. However, these studies only depend on self-reported data from health surveys or focus group discussions.

There is a paucity of studies that have investigated the determinants of screening coverage in a setting that has BC screening in and outside BCSP. The aim of this study therefore was to evaluate the factors associated with the coverage rate of mammography screening and factors that contribute to women's choice of screening in and outside the BCSP using municipality level aggregated data.

\section{Methods \\ Screening in Flanders}

Flanders, the most populated region of Belgium, established a BCSP for women aged 50-69 in 2001 [5]. The organization and implementation of mammography screening in and outside the BCSP in Flanders have been described in detail elsewhere [5, 23, 24]. Briefly, in BCSP, every 2 years, eligible women aged 50-69 are actively recruited through a personalized invitation letter sent by the Center for Cancer Detection in Flanders with a fixed time and place for a digital mammography screening fully and directly paid by the health insurance system in Flanders. The Flemish program follows the European quality assurance guidelines [9]. Mammography screening outside the context of the BCSP can be accessed by a referral from a general practitioner (GP) or a gynecologist, is not fully covered by health insurance [5], and does not systematically include quality-control activities (e.g. double reading) [5]. Since 2016, women who received reimbursement for mammography in the last 2 years from the health insurance or have been diagnosed with $\mathrm{BC}$ in the last 10 years in the Flemish health care system are not invited for the population screening program.

\section{Data description}

Municipality level screening coverage in 2008-2016 was calculated using data from the Center for Cancer Detection in Flanders [25]. Municipalities that have no missing values of the number of screened and nonscreened women were included in the study. Independent variables at the municipality level of 2008-2016 were derived from the database of the Flemish provincial authorities and linked to data of the screening coverage. We included only the variables that were 
publicly available in order to reduce the bias that may be induced by the selection of variables [26].

\section{Privacy considerations}

Privacy was warranted since only aggregated data were available at municipality level and for municipalities with less than 5 screened women overall or in one of the four age groups (50-54, 55-59, 60-64, and 65-69), a missing value was used.

\section{Main outcome}

The main outcome of our analysis was the screening coverage rate inside and outside the BCSP from 2008 to 2016. The coverage rate was presented overall as a median value over all years and municipalities and stratified by age groups and the two screening strategies.

\section{Determinants considered}

For an overview of the variables considered in the analysis, see Table 1. Number of residents and population density were defined as the total number of residents and the number of residents per $\mathrm{km}^{2}$ per municipality, respectively. Natural balance was defined as the natural growth per 1000 residents per municipality. Residential stability was indicated by the percentage of residents having the same address as the year before. Non-Belgian nationality was defined as the percentage of residents without a Belgian nationality per municipality. The socioeconomic status (SES) of residents was characterized by the following four proxy variables: (1) Average household size was defined as the average number of residents per households as a proxy for crowded housing conditions. (2) Women with equivalent living wages was defined as the percentage of women with equivalent living wages which is the minimum income awarded by the social welfare center. (3)Share of borrowers with at least one overdue loan was defined as the percentage of borrowers with at least one overdue loan per municipality where a high percentage was considered as a proxy for poverty; and (4)Job seekers were defined as the percentage of unemployed residents with waiting allowance or bridging allowance per municipality. Health status was indicated by residents aged 18-64 with physical disability or status of diabetes, and defined as the percentage of handicapped residents aged 18-64 and the percentage of residents with diabetes recognized by the health insurance system, respectively. Healthy behavior was indicated by dental visit defined as the percentage of residents having at least 2 visits at the dentist in 2 different years within a period of 3 calendar years per municipality.

\section{Statistical analysis}

Median value and interquartile range (IQR): p25-p75 were calculated for all continuous variables which were not normally distributed. The annual screening coverage rate inside and outside the BCSP was calculated as a median value over all years and municipalities and presented overall and stratified by four age groups: 50-54, 55-59, 60-64, and 65-69. To evaluate which determinants were related to the annual

Table 1 Social demographic parameters of Flanders per municipality in the period 2008-2016. In total 295 municipalities were included

Median (P25-P75)

\begin{tabular}{|c|c|}
\hline \multicolumn{2}{|l|}{ Population and households } \\
\hline number of residents ( $10^{5}$ residents) & $0.15(0.10-0.22)$ \\
\hline population density (1000 residents per $\mathrm{km}^{2}$ ) & $0.41(0.27-0.66)$ \\
\hline natural balance (per 1000 residents) & $0.86(-0.76-2.43)$ \\
\hline same address as last year (compared to all residents)\% & $92.50(91.40-93.30)$ \\
\hline non-Belgian nationality (compared to all residents)\% & $3.30(2.10-6.00)$ \\
\hline average household size & $2.44(2.37-2.51)$ \\
\hline \multicolumn{2}{|l|}{ Welfare and poverty (\%) } \\
\hline women with equivalent living wages (compared to all women residents) & $0.26(0.18-0.41)$ \\
\hline share of borrowers with at least one overdue loan (compared to all borrowers) & $3.00(2.50-3.80)$ \\
\hline job seekers (compared to all residents)\% & $1.80(1.40-2.20)$ \\
\hline \multicolumn{2}{|l|}{ Health and handicap (\%) } \\
\hline person with physical disability18-64y (compared to all residents in 18-64y) & $1.96(1.57-2.58)$ \\
\hline diabetes (compared to all residents) & $5.10(4.60-5.60)$ \\
\hline dental visit (compared to all residents) & $54.50(51.30-57.70)$ \\
\hline
\end{tabular}


coverage of the two screening strategies, a logistic regression model with generalized estimating equations (GEE) was constructed to account for the correlation of repeated measurements of municipality level screening coverage rate and social demographic parameters. In the GEE model, the dependent variable was the municipality level coverage rate and the independent variables were the municipality level social demographic parameters as given in Table 1. A binary variable that indicated the type of screening strategy that the coverage rate referred to was provided and used as an independent variable. Odds ratios (OR) were reported with 95\% confidence interval (CI). The effect of social demographic parameters was investigated by assessing a two-way interaction between the two screening strategies and the significant independent variables. All statistical analyses were performed using $\mathrm{R}$ version 3.6.0, and a two-sided $P<0.05$ was considered statistically significant.

\section{Results}

We included 295 of the 308 municipalities in Flanders that reported full data of the number of screened women of the two screening strategies in all age groups in 2008-2016. The median percentages of all included social demographic parameters over all years and municipalities are shown in Table 1.The overall median coverage of all years and municipalities of both screening strategies combined was $60.90 \%$. The median coverage rates of all years and municipalities inside and outside the BCSP were $48.40 \%$ (IQR: 41.50$54.40 \%$ ) and $14.10 \%$ (IQR: $9.80-19.80 \%$ ) respectively, Table 2. The median coverage of screening outside the BCSP decreased from 2008 to 2016, especially in the youngest age group, while an increase of screening coverage inside the BCSP was seen in all age groups, Fig. 1.

From the univariate analysis it followed that significantly less women were screened outside the BCSP than inside the BCSP (OR: 0.184, 95\% CI: 0.1800.189 ). The probability of being screened in or outside the BCSP was positively associated with the average household size (OR: 1.282, 95\% CI: 1.138-1.444), while negatively associated with the percentage of women with equivalent living wages (OR: 0.899, 95\% CI: 0.855-0.945), the percentage of unemployed job seekers (OR: 0.961, 95\% CI: 0.936-0.987) and population density (OR: 0.918, 95\% CI: 0.888-0.949). (Table 3). After the adjustment for social demographic parameters in the multivariate analysis, the probability of being screened inside or outside the BCSP was only negatively associated with average household size (OR: 0.894, 95\% CI: 0.809-0.988), population density (OR: 0.929, 95\% CI: 0.906-0.952), and diabetes prevalence (OR: $0.964,95 \%$ CI: $0.952-0.976)$ whereas positively associated with the percentage of unemployed job seekers (OR: 1.073, 95\% CI: 1.051-1.095), and the percentage of residents with proper dental care (OR: 1.005, 95\% CI: 1.003-1.007) (Table 4).

Contrary to the BCSP, the probability of being screened outside the BCSP was positively associated with being in a younger age group, a high population density (OR: 2.528, 95\% CI: 2.455-2.606), and a larger households size (OR: 3.797, 95\% CI: 3.199-4.508), and negatively associated with the diabetes prevalence (OR: 0.942, 95\% CI: 0.921-0.962), the percentage of unemployed job seekers (OR: 0.641, 95\% CI: 0.624-0.658) and the percentage of residents with proper dental care (OR: 0.969, 95\% CI: 0.967-0.972) (Table 4).

\section{Discussion}

In the present study, we assessed the coverage determinants of screening inside and outside the BCSP in Flanders. A median $48.4 \%$ of women aged 50-69 are screened by the BCSP which is significantly higher than the $14.1 \%$ of women screened outside the program. Working women in younger age group (50-54 years of age), and women living in crowded households with low dental care go less frequently to the screening, and if they go, they tend to be screened more frequently outside the context of the BCSP.

Table 2 Median screening coverage (P25-P27) in Flanders

\begin{tabular}{lll}
\hline & \multicolumn{2}{c}{ Screening coverage (\%): Median (P25-P75) } \\
\cline { 2 - 3 } & Population BC screening & Non-population BC screening \\
\hline Overall & $48.40(41.50-54.40)$ & $14.10(9.80-19.80)$ \\
Age group & & $17.50(13.00-24.10)$ \\
50-54 year & $45.40(37.50-51.30)$ & $14.30(10.00-20.50)$ \\
55-59year & $50.10(42.80-56.10)$ & $13.50(9.30-18.70)$ \\
$60-64$ year & $50.10(43.60-56.20)$ & $11.40(8.20-16.00)$ \\
$65-69$ year & $47.80(42.40-53.40)$ & \\
\hline
\end{tabular}




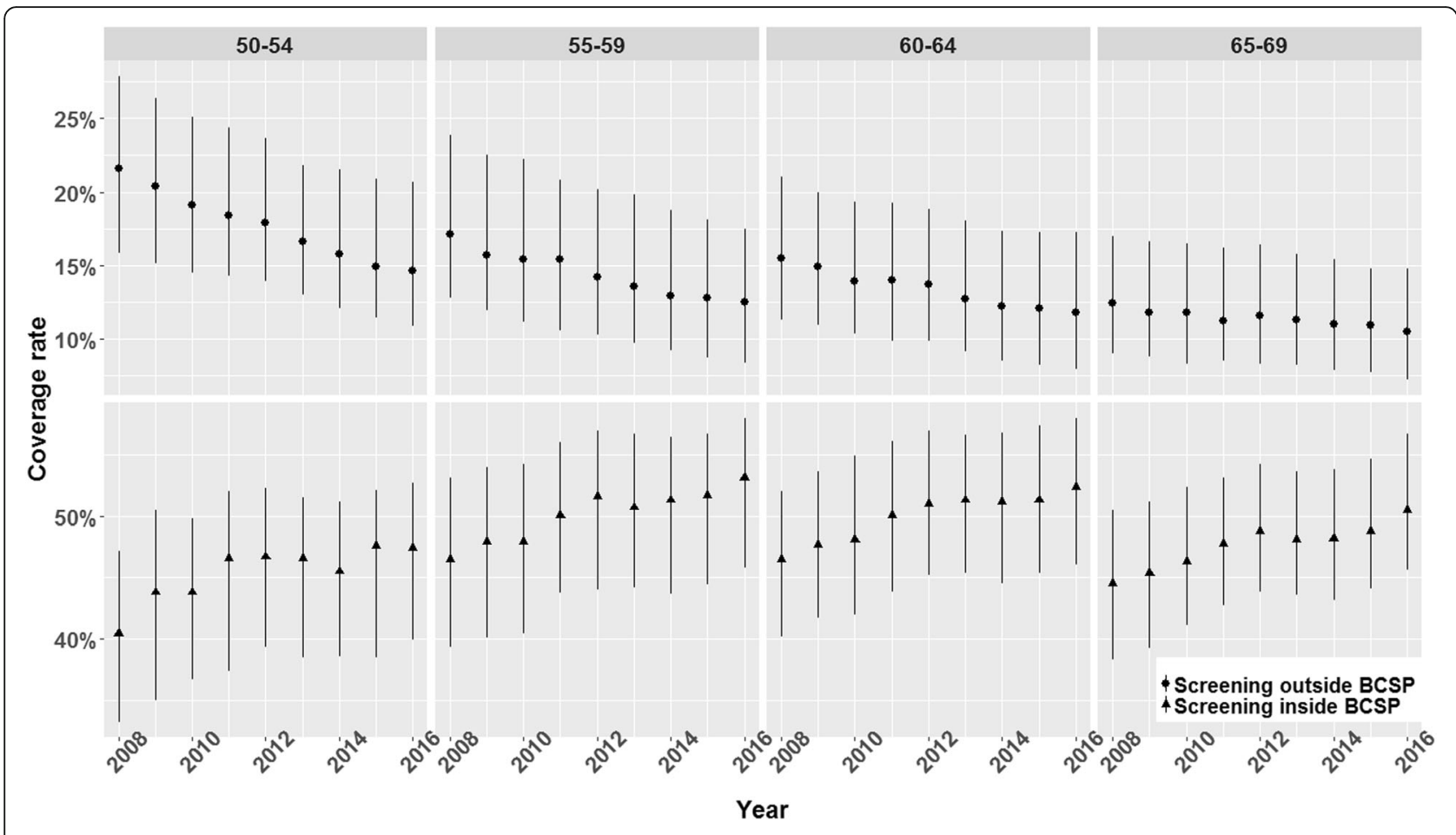

Fig. 1 Median (P25-P75) screening coverage rate of 295 municipalities by age groups in 2008-2016

The total median coverage rate of $60.90 \%$ of screening inside and outside the BCSP is within the range of coverage levels of European countries (average: $48.2 \%$ (range: 19.4-88.9\%)) [27]. The median coverage rate of the BCSP in Flanders of $48.4 \%$ is close to the coverage rate of the BCSP in countries such as France (52.8\%) [6] and Switzerland $(46.7 \%)[7,27]$ and higher than in Serbia (38.0\%) [28]. In these three countries there is screening in and outside the context of the BCSP. However, it is much lower than the coverage rate of the BCSP in some western and northern European countries like the United Kingdom (78.0\%), the Netherlands (78.5\%), and Norway (72.1\%) [27] where only the BCSP is endorsed as the population screening strategy.

From 2006 to 2016, the coverage rate of BCSP increased while the coverage rate outside the BCSP decreased. This effect might be explained by public health campaigns via mass media and community education programs [24, 29], which increased the visibility and awareness of BCSP for the target population and their doctors $[29,30]$. A decrease in screening coverage rate was observed from 17.50 to $11.40 \%$ for the individuals from age 50-54 to 65-69 years old in the screening outside the BCSP, whereas this pattern was not observed for the individuals in the BCSP. A similar pattern is also observed in countries like France $[6,31]$ and the United States of America [32] where both screening strategies are provided in large scale. A potential explanation can be that older women are more likely to attend the relatively fixed time and place of the BCSP than younger working women.

We found that living in crowded households, living in an area with high population density, and having a low dental care are associated with a lower probability of being screened. These three characteristics are all indicators for a low SES. People living in areas with a high population density tend to have a lower SES [33]. People living in crowded household are more likely to fall into income poverty [34]. As dental care is not fully covered by the health insurance system in Flanders [35], a low dental care indicates a lower SES [36]. Similar associations are also available in the literature regarding the increased BCSP coverage and increased dental care [19], less crowded household condition [14], and decreased population density [37].

Interestingly, women that are characterized by living in an area with high population density, living in a more crowded households, or having a low dental care tend to go more frequently for screening outside the BCSP. The reverse SES gradient in the use of screening 
Table 3 Univariate analysis of the determinants of screening in or outside the population BC screening

\begin{tabular}{|c|c|c|}
\hline Variable & Crude OR $(95 \% \mathrm{Cl})$ & $P$ value \\
\hline Year & $1.002(0.996-1.008)$ & 0.534 \\
\hline Age group & & $<0.001$ \\
\hline $50-54$ year & ref & \\
\hline $55-59$ year & $1.034(0.993-1.077)$ & \\
\hline 60-64 year & $1.014(0.973-1.057)$ & \\
\hline 65-69year & $0.933(0.894-0.973)$ & \\
\hline BC screening & & $<0.001$ \\
\hline Population BC screening & ref & \\
\hline Non-population BC screening & $0.184(0.180-0.189)$ & \\
\hline \multicolumn{3}{|l|}{ Population and households } \\
\hline number of residents ( $10^{5}$ residents) & $0.962(0.941-0.983)$ & $<0.001$ \\
\hline population density (1000 residents per $\mathrm{km}^{2}$ ) & $0.918(0.888-0.949)$ & $<0.001$ \\
\hline natural balance (per 1000 residents) & $0.996(0.990-1.002)$ & 0.194 \\
\hline same address as last year (compared to all residents) & $1.024(1.013-1.035)$ & $<0.001$ \\
\hline non-Belgian nationality (compared to all residents) & $0.996(0.993-0.999)$ & 0.016 \\
\hline average household size & $1.282(1.138-1.444)$ & $<0.001$ \\
\hline \multicolumn{3}{|l|}{ Welfare and poverty } \\
\hline women with equivalent living wages (compared to all women) & $0.899(0.855-0.945)$ & $<0.001$ \\
\hline share of borrowers with at least one overdue loan (compared to all borrowers) & $0.970(0.958-0.982)$ & $<0.001$ \\
\hline job seekers (compared to all residents) & $0.961(0.936-0.987)$ & 0.004 \\
\hline \multicolumn{3}{|l|}{ Health and handicap } \\
\hline physical disability18-64y (compared to all residents of 18-64y) & $1.003(0.986-1.021)$ & 0.701 \\
\hline diabetes (compared to all residents) & $0.972(0.954-0.991)$ & 0.003 \\
\hline dental visit (compared to all residents) & $1.009(1.006-1.012)$ & $<0.001$ \\
\hline
\end{tabular}

in and outside BCSP was also seen in other settings where both screening strategies coexist $[6,7,37]$. An explanation for this phenomenon is that women with a higher SES are more likely to have a higher level of health literacy [38]. For these women, information regarding the importance of mammography screening and the systematic quality control is more likely to motivate them to participate in the BCSP [5] [29]. Another explanation is that poor employed women could have less flexible working time, which can conflict with the fixed working time of organized screening units $[6,7$, 37, 39]. It has also been mentioned that areas with a higher population density have a lower population BC screening capacity (defined as the number of mammography facilities per 10,000 women) [40] and that in these areas there are more private clinics for opportunistic screening [37]. As a lower capacity of screening units can induce a longer waiting time and therefore a lower satisfaction of screening experience [5], low SES women living in these areas might be more likely to have negative screening experience and as a consequence prefer to go for screening outside the BCSP [22].
The strength of this study is that we examined determinants of coverage rate of screening in and outside the BCSP with longitudinal administrative data instead of self-reported screening uptake, which may induce recall bias. For that, regular collected and maintained administrative data of screening coverage outside the BCSP were applied. This enabled us to evaluate the determinants of the two coexisting screening strategies for $\mathrm{BC}$ and to better understand which further efforts are needed to improve the coverage of the BCSP in Flanders. However, our study had some limitations as well. First, a limitation of this study was the use of aggregated data, which reduced the options to evaluate correlation structures in the data [41]. Similarly, due to the aggregated data, a variation of coverage rate and the associated determinants within a municipality can be concealed. However, the association between the determinants and screening uptake in our study is consistent with other studies that applied neighborhood or individual level factors $[13,18,19]$. Second, proxy variables for SES were applied instead of income which can directly characterize SES of women. However, the 
Table 4 Multivariable analysis of the determinants of screening in or outside the population BC screening

\begin{tabular}{|c|c|c|c|c|}
\hline \multirow[t]{2}{*}{ Variable } & \multicolumn{2}{|l|}{ Model $1^{\text {a }}$} & \multicolumn{2}{|l|}{ Model $2^{b}$} \\
\hline & Adjusted OR (95\% Cl) & $P$ value & Adjusted OR (95\% Cl) & $P$ value \\
\hline Age group & & $<0.001$ & & $<0.001$ \\
\hline $50-54$ year & ref & & ref & \\
\hline 55-59year & $1.039(1.015-1.065)$ & & $1.207(1.179-1.235)$ & \\
\hline 60-64 year & $1.018(0.994-1.042)$ & & $1.217(1.190-1.244)$ & \\
\hline 65-69year & $0.928(0.907-0.949)$ & & $1.142(1.117-1.167)$ & \\
\hline BC screening & & $<0.001$ & & $<0.001$ \\
\hline Population BC screening & ref & & ref & \\
\hline Non-population BC screening & $0.224(0.220-0.229)$ & & $0.303(0.295-0.312)$ & \\
\hline \multicolumn{5}{|l|}{ Population and households } \\
\hline number of residents ( $10^{5}$ residents) & $0.983(0.965-1.001)$ & 0.059 & $0.996(0.985-1.007)$ & 0.444 \\
\hline population density (1000 residents per $\mathrm{km}^{2}$ ) & $0.929(0.906-0.952)$ & $<0.001$ & $0.647(0.634-0.660)$ & $<0.001$ \\
\hline same address as last year (compared to all residents) & $1.008(0.998-1.018)$ & 0.123 & $1.005(0.995-1.015)$ & 0.309 \\
\hline non-Belgian nationality (compared to all residents) & $1.0005(0.9984-1.0025)$ & 0.654 & $0.9997(0.9982-1.0012)$ & 0.719 \\
\hline average household size & $0.894(0.809-0.988)$ & 0.028 & $0.580(0.522-0.645)$ & $<0.001$ \\
\hline \multicolumn{5}{|l|}{ Welfare and poverty } \\
\hline $\begin{array}{l}\text { women with equivalent living wages } \\
\text { (compared to all women) }\end{array}$ & $0.972(0.934-1.012)$ & 0.164 & $0.987(0.947-1.029)$ & 0.532 \\
\hline $\begin{array}{l}\text { share of borrowers with at least one overdue loan } \\
\text { (compared to all borrowers) }\end{array}$ & $0.989(0.976-1.002)$ & 0.092 & $0.989(0.978-1.001)$ & 0.067 \\
\hline job seekers (compared to all residents) & $1.073(1.051-1.095)$ & $<0.001$ & $1.250(1.226-1.273)$ & $<0.001$ \\
\hline \multicolumn{5}{|l|}{ Health can handicap } \\
\hline diabetes (compared to all residents) & $0.964(0.952-0.976)$ & $<0.001$ & $0.985(0.973-0.997)$ & 0.016 \\
\hline dental visit (compared to all residents) & $1.005(1.003-1.007)$ & $<0.001$ & $1.016(1.015-1.018)$ & $<0.001$ \\
\hline \multicolumn{5}{|l|}{ Interaction terms } \\
\hline age group $\times B C$ screening & & & & $<0.001$ \\
\hline NPS $\times 50-54$ year & & & ref & \\
\hline NPS $\times 55-59$ year & & & $0.668(0.642-0.694)$ & \\
\hline NPS $\times 60-64$ year & & & $0.612(0.589-0.636)$ & \\
\hline NPS $\times 65-69$ year & & & $0.554(0.533-0.576)$ & \\
\hline NPS $\times$ population density & & & $2.528(2.455-2.606)$ & $<0.001$ \\
\hline NPS $\times$ average household size & & & 3.797 (3.199-4.508) & $<0.001$ \\
\hline NPS $\times$ job seekers & & & $0.641(0.624-0.658)$ & $<0.001$ \\
\hline NPS $\times$ status of diabetes & & & $0.942(0.921-0.962)$ & $<0.001$ \\
\hline NPS $\times$ dental visit & & & $0.969(0.967-0.972)$ & $<0.001$ \\
\hline
\end{tabular}

${ }^{a}$ model 1: multivariable regression model including all significant covariates of the univariate regression

${ }^{b}$ model 2: multivariable regression model including two-way interaction terms between screening strategies and the significant covariates in model 1 NPS Non-population BC screening

proxy variables used are commonly applied and the magnitude and direction of the association between variables is consistent with the literature $[6,14,18]$.

\section{Conclusion}

A sizeable part of women attend screening outside the BCSP in Flanders. Women with low SES that are characterized by younger age, living in a high population density area, living in crowded households, or having low dental care, go less frequently to screening. If they go to screening, they are more likely to be screened outside the BCSP. Further efforts targeted on this group of women are needed to improve the coverage rate of the BCSP in Flanders. 


\section{Abbreviations}

BC: Breast cancer; BCSP: Breast cancer screening program; GP: General practitioner; SES: Socioeconomic status; IQR: Interquartile range; GEE: Generalized estimating eqs.; OR: Odds ratios; Cl: Confidence interval

\section{Acknowledgements}

L. Ding is supported by the China Scholarship Council (CSC) PhD scholarship (file NO. 201808320439) for his research and study at the University of Groningen, University Medical Center Groningen, Groningen, The Netherlands. The scholarship had no role in study design, data analysis and interpretation, the writing of the manuscript and the decision to submit the article for publication.

\section{Authors' contributions}

L. Ding: Conceptualization, Methodology, Writing- Original draft preparation. S. Jidkova: Data curation, Writing- Reviewing and Editing, Validation. M.J.W. Greuter: Conceptualization, Methodology, Writing- Reviewing and Editing. G.H. de Bock: Supervision. K. Van Herck: Writing- Reviewing and Editing, Validation. M. Goossens: Writing- Reviewing and Editing, Validation. P. Martens: Writing- Reviewing and Editing, Validation. G. Van Hal: Conceptualization, Methodology, Writing- Reviewing and Editing. The author(s) read and approved the final manuscript.

\section{Funding}

None.

\section{Availability of data and materials}

Breast cancer screening coverage dataset is available at https:// bevolkingsonderzoek.incijfers.be/, variables regarding the determinants of screening coverage can be requested by contacting the Center for Cancer Detection in Flanders at www.bevolkingsonderzoek.be.

\section{Ethics approval and consent to participate}

Not applicable.

\section{Consent for publication}

All authors have approved the manuscript and agree with this submission.

\section{Competing interests}

None.

\section{Author details}

'Department of Epidemiology, University Medical Center Groningen, University of Groningen, Groningen, The Netherlands. ${ }^{2}$ Department of Social Epidemiology and Health Policy, University of Antwerp, Antwerp, Belgium. ${ }^{3}$ Department of Public Health and Primary Care, Ghent University, Ghent, Belgium. ${ }^{4}$ Center for Cancer Detection, Flanders, Belgium. ${ }^{5}$ Department of Radiology, University Medical Center Groningen, University of Groningen, Groningen, The Netherlands. 'Department of Robotics and Mechatronics, University of Twente, Enschede, The Netherlands.

Received: 13 April 2020 Accepted: 11 November 2020

\section{Published online: 27 November 2020}

\section{References}

1. Bray F, et al. Global Cancer Statistics 2018: GLOBOCAN estimates of incidence and mortality worldwide for 36 cancers in 185 countries: global Cancer statistics 2018. CA Cancer J Clin. 2018;68(6):394-424.

2. International Agency for Research on Cancer. CANCER TODAY: Population fact sheets-Belgium, http://gco.iarc.fr/today/data/factsheets/populations/56belgium-fact-sheets.pdf; 2018[Accessed 3 February 2020].

3. Myers ER, et al. Benefits and harms of breast Cancer screening: a systematic review. JAMA. 2015;314(15):1615-34.

4. Lauby-Secretan B, et al. Breast-Cancer screening - viewpoint of the IARC working group. N Engl J Med. 2015;372(24):2353-8.

5. Goossens $M$, et al. Quantifying independent risk factors for failing to rescreen in a breast cancer screening program in Flanders, Belgium. Prev Med. 2014:69:280-6.

6. Duport N. Characteristics of women using organized or opportunistic breast cancer screening in France. Analysis of the 2006 French health, health care and insurance survey. Rev Epidemiol Sante Publique. 2012;60(6):421-30.
7. Eichholzer M, et al. Breast cancer screening attendance in two Swiss regions dominated by opportunistic or organized screening. BMC Health Serv Res. 2016;16(1):519.

8. Massat $\mathrm{N}$, et al. Variation in cervical and breast cancer screening coverage in England: a cross-sectional analysis to characterise districts with atypical behaviour. BMJ Open. 2015;5:e007735.

9. Perry $N$, et al. European guidelines for quality assurance in breast cancer screening and diagnosis. Fourth edition--summary document. Ann Oncol. 2008;19(4):614-22

10. OECD.Stat, Health Care Utilisation. https://stats.oecd.org/Index. aspx?DataSetCode=HEALTH_PROC. Accessed 3 Feb 2020.

11. Annual Report Population Screening for Cancer 2018. Center for Cancer detection-Belgian Cancer registry, Bruges, 2018.

12. Sarma EA. Barriers to screening mammography. Health Psychol Rev. 2015; 9(1):42-62.

13. Katz D, et al. Patient and physician characteristics affect adherence to screening mammography: a population-based cohort study. PLoS One. 2018;13(3):12

14. Zackrisson S, et al. Non-attendance in breast cancer screening is associated with unfavourable socio-economic circumstances and advanced carcinoma. Int J Cancer. 2004;108(5):754-60.

15. Jensen LF, et al. Identifying specific non-attending groups in breast cancer screening - population-based registry study of participation and sociodemography. BMC Cancer. 2012;12:9.

16. Smith $D$, et al. The breast cancer paradox: a systematic review of the association between area-level deprivation and breast cancer screening uptake in Europe. Cancer Epidemiol. 2019;60:77-85.

17. Pornet C, et al. Socioeconomic and healthcare supply statistical determinants of compliance to mammography screening programs: a multilevel analysis in Calvados, France. Cancer Epidemiol. 2010;34(3):309-15.

18. Zackrisson S, et al. Social predictors of non-attendance in an urban mammographic screening programme: a multilevel analysis. Scand J Public Health. 2007;35(5):548-54.

19. von Euler-Chelpin $M$, et al. Socio-demographic determinants of participation in mammography screening. Int J Cancer. 2008;122(2):418-23.

20. Zha N, et al. Beyond Universal Health Care: Barriers to Breast Cancer Screening Participation in Canada. J Am Coll Radiol. 2019;16(4 Pt B): $570-9$

21. Miles RC, et al. Chronic medical illness as a risk factor for poor mammography screening adherence. J Women's Health (Larchmt). 2019; 28(10):1378-83.

22. Ferrat $\mathrm{E}$, et al. Understanding barriers to organized breast cancer screening in France: women's perceptions, attitudes, and knowledge. Fam Pract. 2013; 30(4):445-51.

23. Van Oyen $\mathrm{H}$, Verellen W. Breast cancer screening in the Flemish region, Belgium. Eur J Cancer Prev. 1994;3(Suppl 1):7-12.

24. Willems B, Bracke $P$. The impact of regional screening policies on the diffusion of cancer screening participation in Belgium: time trends in educational inequalities in Flanders and Wallonia. BMC Health Serv Res. 2018;18(1):943.

25. Goossens $M$, et al. Flemish breast cancer screening programme: 15 years of key performance indicators (2002-2016). BMC Cancer. 2019;19(1):1012.

26. Portnov BA, Dubnov J, Barchana M. On ecological fallacy, assessment errors stemming from misguided variable selection, and the effect of aggregation on the outcome of epidemiological study. J Expo Sci Environ Epidemiol. 2007;17(1):106-21.

27. Giordano L, et al. Mammographic screening programmes in Europe: organization, coverage and participation. J Med Screen. 2012;19(Suppl 1):72-82.

28. Jovicevic $A$, et al. Factors influencing participation in breast cancer opportunistic screening in Belgrade, Serbia. J Buon. 2018;23(3):706-12.

29. Wouters M, Vleminckx F, Van Hal G. How to reach a higher participation rate for breast cancer screening in Flanders? Arch Public Health Brussels. 2006:64(2/3):109-21.

30. Rogers, E.M. Diffusion of innovations.5th ed. New York: Free Press; 2003.

31. Ouedraogo S, et al. Breast cancer screening programmes: challenging the coexistence with opportunistic mammography. Patient Educ Couns. 2014; 97(3):410-7.

32. Beaber EF, et al. Multilevel predictors of continued adherence to breast cancer screening among women ages $50-74$ years in a screening population. J Women's Health. 2019;28(8):1051-59. 
33. Zhu Z, et al. The impact of urban characteristics and residents' income on commuting in China. Transp Res Part D: Transp Environ. 2017;57:474-83.

34. Melki IS, et al. Household crowding index: a correlate of socioeconomic status and inter-pregnancy spacing in an urban setting. J Epidemiol Community Health. 2004;58(6):476.

35. Lambert MJ, et al. Socioeconomic inequalities in caries experience, care level and dental attendance in primary school children in Belgium: a crosssectional survey. BMJ Open. 2017;7(7):e015042.

36. Kailembo A, et al. Income and wealth as correlates of socioeconomic disparity in dentist visits among adults aged 20 years and over in the United States, 2011-2014. BMC Oral Health. 2018;18(1):147.

37. Jensen $\mathrm{A}$, et al. Do nonattenders in mammography screening programmes seek mammography elsewhere? Int J Cancer. 2005;113(3):464-70.

38. Guo Y, et al. Health literacy: a pathway to better oral health. Am J Public Health. 2014:104(7):e85-91.

39. Collie-Akers VL, et al. Assessment of characteristics of capacity among breast cancer screening facilities. J Community Health. 2012;37(3):626-31.

40. Elkin $E B$, et al. Changes in the availability of screening mammography, 20002010. Cancer. 2013;119(21):3847-53.

41. Russo L, Beauguitte L. Aggregation level matters: evidence from French electoral data. Qual Quant. 2014;48(2):923-38.

\section{Publisher's Note}

Springer Nature remains neutral with regard to jurisdictional claims in published maps and institutional affiliations.

Ready to submit your research? Choose BMC and benefit from:

- fast, convenient online submission

- thorough peer review by experienced researchers in your field

- rapid publication on acceptance

- support for research data, including large and complex data types

- gold Open Access which fosters wider collaboration and increased citations

- maximum visibility for your research: over $100 \mathrm{M}$ website views per year

At BMC, research is always in progress.

Learn more biomedcentral.com/submissions 